\title{
Lawel e dad tô de lagad: An Ethnography of the Collective Wisdom of the Blaans on Disaster Management and Environmental Conservation Jovanie Camacho Espesor ${ }^{1}$
}

\author{
${ }^{1}$ Department of Political Science, College of Social Sciences and Humanities \\ Mindanao State University, General Santos City; Macmillan Brown Centre for Pacific Studies, \\ University of Canterbury, Christchurch, New Zealand, jovanie.espesor@pg.canterbury.ac.nz
}

Received: July 11, 2017; Accepted: December 23, 2017

\begin{abstract}
The Blaan communities in the hinterlands of Sarangani are continually exposed to different forms and types of environmental hazards. These hazards are brought about by disasters such as droughts, landslide, soil erosion, flooding and infestation of rats and swarm of locusts on agricultural crops. This paper seeks to provide a thick and rich description of the indigenous knowledge of the Blaans on disaster management and environmental conservation. It discusses and analyzes various environmental hazards identified and experienced by the Blaans in the mountain ecosystems of Sarangani. Another aim of this study is to analyze the function of the social network of the tribe and their coping mechanisms in confronting the effects of natural disasters. This study utilizes first-hand information that are gathered through intensive ethnographic field observations in the hinterlands of Sarangani. Participatory Rapid Field Appraisal strategies were used to engage the members of the community as primary participants of the study. Moreover, key informant interviews among senior members of Blaan tribes and focus group discussions are used to supplement information generated through participatory research approaches. This study concludes that the Blaans in the mountainous parts of Sarangani have immense collective wisdom on disaster management and environmental conservation, which they have learned from their forefathers. Nonetheless, this vast knowledge system of the Blaans is gradually eroding due to dwindling interest of the younger generations and disappearance of the natural landscape that serves as the social laboratory for the Blaans to learn about the kanfulong de tribu.
\end{abstract}

Keywords: indigenous knowledge, Blaans, Sarangani, disaster management, mountain ecosystem

The Philippines is a part of the Pacific Ring of Fire, which makes the country vulnerable to different types of hydro-meteorological hazards. The International Federation of the Red Cross and Red Crescent (IFRC) reported that the Philippines is visited by at least 20 major storms each year (2015: 5). In the 2016 World Risk Report published by the Institute for Environment and Human Security of the United Nations University, the Philippines ranks third among 171 countries in the world, which have high levels of exposures and vulnerabilities to different types of hazards (Mucke, 2016: 11). With its archipelagic feature, the Philippines is doubly susceptible to the harsh impacts of climate change and various environmental hazards considering that most Filipinos are dependent on fishery and agriculture for their livelihoods.

A major segment of the Philippine popula- tion that is highly vulnerable to natural disasters is the indigenous cultural community (ICC), particularly those located in the mountainous regions of the country. The Disaster Risk Reduction and Management Act of 2010 provides a paramount attention to vulnerable and marginalized groups, including the indigenous peoples (IP). This law serves as a social protection policy that mandates the government to create mechanisms that are designed to build community disaster resilience of vulnerable groups, particularly the IPs. Nonetheless, the participation of the IPs and giving primacy to indigenous voices in disaster planning and development remains marginalized in the Philippines.

There is an emergent call to pay attention to the roles of the ICC in disaster risk reduction by governments and civil society organizations around the world. The vulnerability of the Philippine archi- 
pelago and its local communities, especially the poor IPs is a compelling reason to recognize and strengthen their wealth of collective wisdom for providing solutions to global problems of increasing disasters and climate change impacts (Shaw, Uy and Baumwoll, 2008). Sadly, however, indigenous knowledge on disaster management is an under-researched area.

Scholars pay attention to the collective wisdom of ethno-linguistic tribes in Africa (UNEP, 2008), and Asian communities such as Pakistan (Komino, 2008), Japan (Takeuchi and Shaw, 2008), Mongolia (Borkhuu, 2008) and Aceh, Indonesia (Syafwina, 2014). In the Philippines, the studies on indigenous knowledge primarily focused on tribal communities in northern Luzon such as the Masadiit people (Mendoza, Guiam and Sambeli, n.d.), the Ivatans of Batanes (Uy and Shaw, 2008) and the Ifugaos of Mountain Province (Butic and Ngildo, 2002). Apparently, there is no scientific investigation done on the collective wisdom of ICC in other parts of the Philippines, particularly in Mindanao, which is home to diverse ethnic groups, particularly the Blaans of Sarangani.

Like many traditional communities in the Asia-Pacific Region, the Blaans have developed, since time immemorial, the kanfulong de tribu or indigenous knowledge that has been tested by time and proven effective in reducing vulnerabilities to disasters and managing unavoidable hazards. This knowledge asset is transmitted from one generation to another and internalized by community members through socialization.

This study has three-fold objectives. First, it seeks to provide a thick and rich description of the kanfulong de tribu of the Blaans on disaster management and environmental conservation. Second, it discusses and analyzes the various forms of environmental hazards, including their seasonality and duration, identified by the Blaans in the hinterlands of Sarangani. Third, this research intends to analyze the function of the social network of the tribe and their coping mechanisms in confronting the effects of hydro-meteorological hazards.

\section{Materials and Methods}

This study utilizes first-hand information that are gathered through intensive ethnographic field observations in the hinterlands of Sarangani from June 2013 to February 2014. Participatory Rapid Field Appraisal strategies, such as transect mapping, Venn diagramming and seasonal calendar methods, were used to engage the members of the community as primary participants of the study. Moreover, key informant interviews among the senior members of Blaan tribe and focus group discussions are used to supplement information generated through participatory research approaches. The hinterland villages of Plinggang, Muling and Pongoleel in Alegria, Alabel, Sarangani Province are the field sites of this study. The initial results of the research had been presented to the members of the said communities and the Provincial Government of Sarangani for verification as to the validity and accuracy of the information presented in this study.

This research has been conducted with Free Prior and Informed Consent (FPIC) of the Blaan people, who have participated in the study. The data from the field are sifted, charted and sorted based on the Framework Analysis of Srivastava and Thompson (2009). In the discussion and analysis of data, the researcher put primary consideration to the emic approach (see Morris, Leung, Ames and Lickel, 1999), by highlighting the perspectives and point of view of the Blaans about their indigenous knowledge systems. By putting emphasis on the insiders' perspectives of the Blaans, the researcher acknowledges this indigenous group as the 'creator of their own culture' (see Tuhiwai-Smith, 2012: 1) Nonetheless, the researcher is also amenable that the analysis might have been influenced by his preconceived perspectives and biases about the subject. Finally, it is the contention here that the Blaans of Plinggang, Muling and Pongoleel in Alegria, Alabel, Sarangani have the inherent birth right and hence, ownership of the collective wisdom on disaster management and environmental conservation that is documented in this research.

\section{Results and Discussions}

Through the conduct of intensive field observations using alternative and participatory research strategies and series of community visits in the Blaan communities in the hinterlands of Sarangani, the researcher was able to obtain data and information about the collective wisdom of the said tribe on disaster management and environmental conservation. The vast amount of data shared and provided by the tribe are sifted, charted and sorted according to key themes and issues. Owing to the ethnographic design of the study, the researcher opted to analyze the richness and thickness of the indigenous knowledge system of the Blaans by paying utmost consideration to the emic component (or from insiders' perspective) of the collective 
wisdom of the tribe. The succeeding sections of this article will discuss the state of health of the Calminda Watershed and its importance to the Blaans. In the discussion of results and findings, the researcher devotes major attention to the key aspects of the collective wisdom on disaster management and environment conservation of the Blaan people. Moreover, the researcher employs network analysis to understand the importance of the existing social structure of these indigenous communities in the mountain ecosystems of Sarangani. Finally, he discusses their coping mechanisms to mitigate the effects of disasters and apparent erosion of the indigenous knowledge systems of the tribe.

\section{The Calminda Watershed and the Blaan com- munity}

The Calminda Watershed is a major water resource located in the hinterlands of Alabel in the Province of Sarangani. As shown in the map (Figure 1), the watershed covers a vast area from the hinterland villages of Datal Anggas, Paraiso and Alegria down to the lowland villages of Bagacay, Poblacion, Maribulan and Kawas. The
Calminda feeds the rivers in low lying areas of Alabel and empties in the Sarangani Bay. The area called by the Blaans as Sufa Lamot is the main source of water that flows through the different tributaries of the watershed. According to The Nature Conservancy (2017), a watershed is an area of land, wherein rain water is drained and accumulated in one location such as rivers, lakes, marshlands and streams. These bodies of water have significant importance to human beings as sources of drinking water, water for growing agricultural crops and for various industrial processes. Watersheds are home to a wide array of fauna and flora. Nonetheless, the deteriorating health of watersheds in different parts of the world are attributed to detrimental human activities that are environmentally destructive. Land management or mismanagement is dictated by human actions that typically takes place in watersheds. Human activities have intensive impacts on the quality of water; health of the aquatic ecosystem; and the entire hydrologic cycle, as well as efforts that are geared towards water conservation (Edwards, 2015; see Hewitt and Mehta, 2012).

The Blaan people in the highland commu-

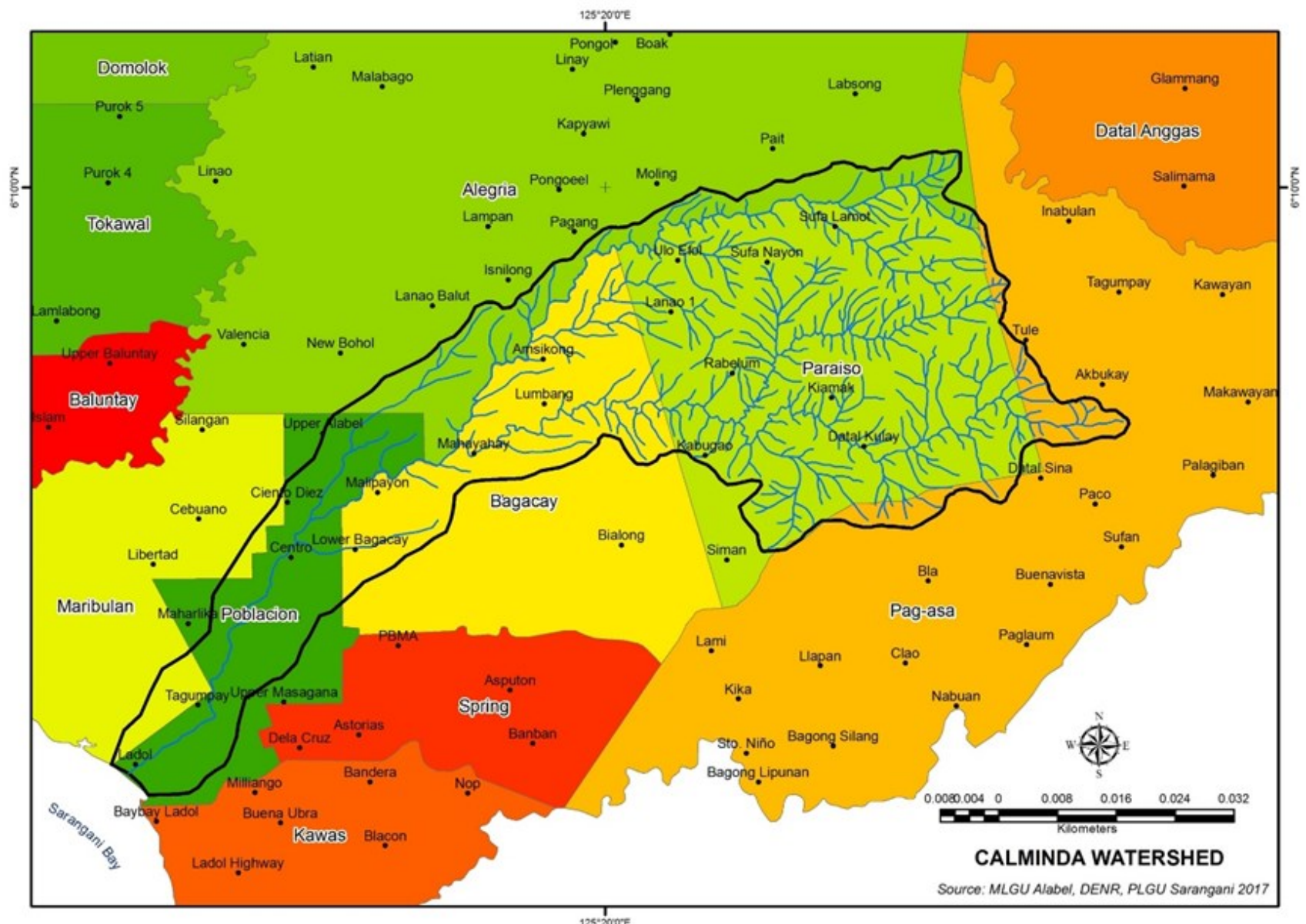

Figure 1. Map of the Calminda Watershed . 
nities of Plinggang, Muling and Pongoleel rever the Calminda Watershed as a sacred ground, which constitutes an integral part of their lives. These peoples are deeply attached to their native lands, especially the mountains, forests and rivers. From an anthropological perspective, it has been observed that many indigenous people around the world perceive themselves to be stewards of the land. They put paramount importance to dwelling together with other living things, especially plants and animals, conserving natural resources and communing with the environment for the benefits of the succeeding generations (Caverley, 2009). Calminda not only supplies water for consumption and household use to the Blaans, but it is also considered by the tribe as a sacred gumlok or hunting grounds. Wild animals are abundant in the area and are usually hunted by the members of the tribe. These wild animals include lablab (wild pig), slarong (deer), unggoy (monkeys), anuk takayo (wild birds) and anuk (wild chicken). Animals such as these usually flock on the banks of the watershed to drink water. Moreover, Calminda is home to a variety of fresh water fishes such as ki'le (eel), kulong (big shrimp), agong (small shrimp), kulo (crab), paitan (milkfish), and ngi'lag (catfish). Unfortunately, the Blaans have noticed a significant reduction in the number of wildlife living in the surrounding forests of the Watershed.

The members of the community reported that the health of the Calminda Watershed is no longer the same as it was before. The volume of water flowing in the watershed has significantly reduced over the years. At present, major tributaries of the Watershed are already dry and no water is flowing, except during heavy rains. The life of the Blaans in the mountain community is deeply intertwined to their lands and the Calminda Watershed. In times of hardships such as domlingo (El Nino or drought season) and simog (La Nina or rainy season) that destroys agricultural crops and results in food insecurity, the community relies on the watershed for food through inland fishing and hunting of wild animals. The dwindling state of health of the watershed is an alarming threat to the survival of the Blaan people. Without the watershed, the community could certainly encounter difficulties when disaster strikes, and consequently, this exposes the members of the community to various environmental hazards.

The social map (Figure 2), which was generated through the participation of community members, shows the Plinggang, Muling and Pongoleel, as well as the nearby Sitios of Malaya and Pagang in the mountain ecosystem in Alegria, Alabel, Sarangani Province. It can be noticed that these communities are built on top of the hill bounded by the Snilong Creek in the north and the Calminda Watershed in the south. The hillsides are utilized by the community folks to grow corn, banana, coconut and other agricultural crops. The riparian zones of the Calminda Watershed are dominated by forest trees and some patches of bamboo. According to the members of the community, their community is a former site of large-scale logging activities, which resulted to the disappearance of forest including all the wild animals and birds that were residing therein. At present, these forest patches are the results of National Greening Program of the

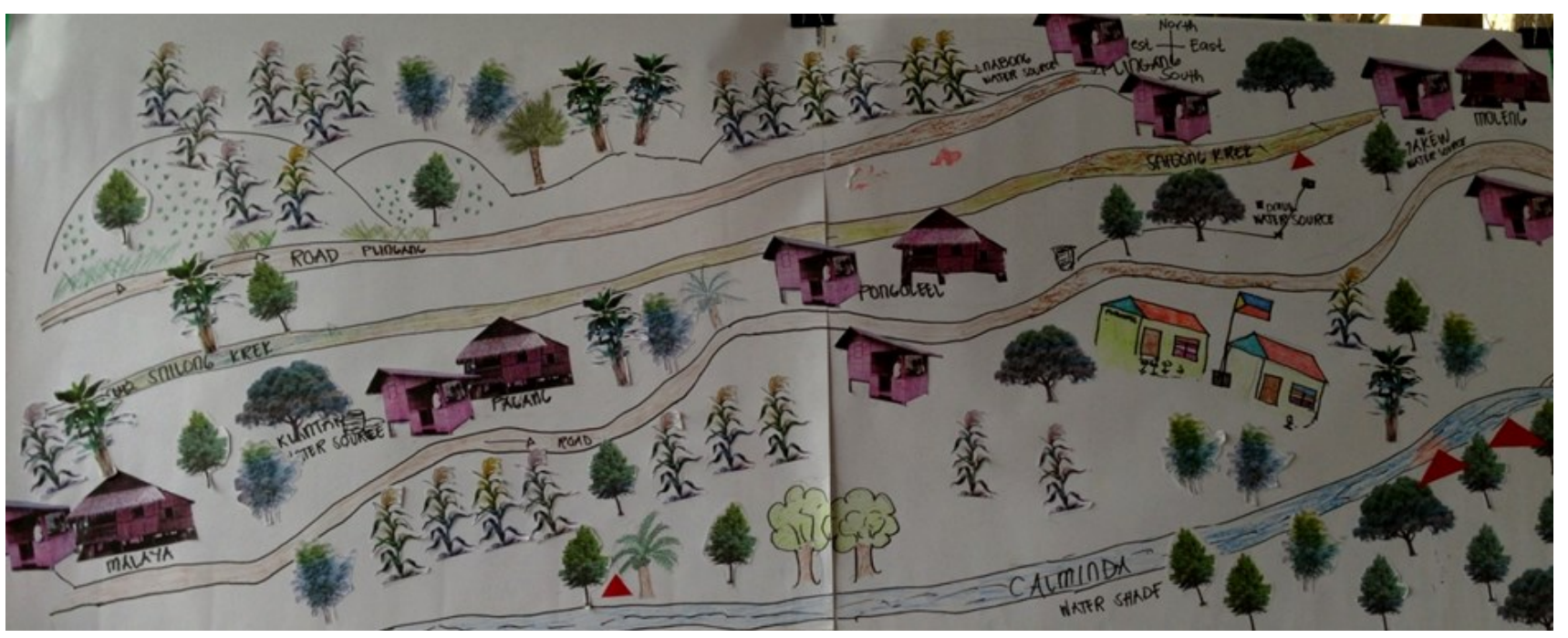

Figure 2. Community Map of the Blaans. 
Department of the Environment and Natural Resources, which tapped the Blaan folks as stewards of the forest and primary agents in this reforestation initiative and restoration effort. The red triangles on the map are the areas in the Snilong Creek and Calminda Watershed, where landslides and soil erosions are typically observed by the members of the community.

Observance of climate change and natural hazards

The members of the community have observed that the pattern of climatic and weather conditions have changed over time. The Blaans are farming communities and are guided by their indigenous farming techniques, which have been transmitted by their ancestors to the current generation. They know the best time of the year when to plant corn and other crops by observing some natural phenomena, particularly the size and position of the moon in the sky, the behavior of trees and animals, and the direction of the wind. Unfortunately, the tribe reported that they could no longer predict the patterns of the weather nowadays. The climate in the present has changed drastically, affecting traditional farming system of the tribe. Thus, the traditional knowledge of predicting the weather, which is a valuable asset of the tribe from their ancestors may no longer be reliable and functional due to climate change.

As shown in the seasonal calendar, the Blaans identify drought as the primary source of environmental hazards which they have confronted over the years. According to them, drought season usually starts in March to middle of April. During drought, crops such as corn, coconut, banana and sweet potato die and result in food insecurity among members of the community. The impact of drought is not only felt by the people, but also by farm animals, particularly cows, goats and carabaos, as grasses for forage wither during this season. To cope with the effects and impacts of drought, the Blaans would gather poisonous wild yam and fufew in the forest for food. They would also hunt wild birds and animals inside the forest and in the riverbanks of the watershed. Every June and July, the Blaans observe the presence of strong wind accompanied by heavy rains that cause destruction of crops and often result in landslides in the area. Consequently, strong wind and heavy rain cause insufficiency of food supplies for members of the community and decrease the quantity of agricultural harvest. During this season, the Blaans eat mlaga, fugan, akil and basag, plants that belong to the palm family and all abundantly grow in the watershed. The community also experience rat infesta- tion, which usually takes place from August to September. Rodents ravage farm crops such as coconut, rice, sweet potato and cassava that result in insufficient supply of food for the community. When rat infestation occurs, foods from the forest like yam, taro, biga, poisonous wild yam, and soft parts of palm trees substitute for the consumption of the community. Finally, the Blaan community has not been spared from locust infestation. From March to May, members of the community have to deal with the swarm of grasshoppers that destroy their crops, especially corn, rice, coconut and banana. Even grasses and bamboo plants are eaten by the locusts. Consequently, the Blaans suffer from inadequate food supply. Even farm animals suffer because of inadequate supply of edible grass for forage. Grasshoppers are aplenty during this season. The Blaans deal with them by eating them to stave off hunger. There were times in the past that rat and locust infestation lasted for two years, heavily devastating the livelihoods of Blaan people in the hinterlands of Sarangani.

Indigenous knowledge on disaster management

In this paper, the researcher documented the cultural richness of the kanfulong de tribu or collective wisdom of the Blaans. This set of indigenous knowledge have been useful to the members of the tribe to survive and mitigate various forms of natural hazards, which constantly confront them over the years. The components of this knowledge asset include ethno-medical practices, indigenous farming system and seed banking, food storage, functional architecture and community-based meteorology.

Plant-based pharmacopoeia for both human and animal health

The knowledge on ethno-medicine or the use of plants for medical purposes by tribal groups in different parts of the world has been documented by researchers, who have keen interest in indigenous knowledge systems (see Ososki, Balick and Daly, 2007; Lundberg, 2007). The Blaans in the hinterlands of Sarangani have profound knowledge on ethno-medicine or the use of plants with pharmacological properties to cure different diseases. The Blaans have been using different plants in treating various forms of illnesses since ancient times. They have learned the art of healing using plants and animals from the surrounding forests from their ancestors, who transmitted these ethnomedical knowledge to the present generation. Traditional healers, who have the know-how to perform indigenous procedures of treating diseases, are mostly women who are birth attendants of the 
Table 1. Typologies of disasters and their seasonality, effects and impacts to the Blaans.

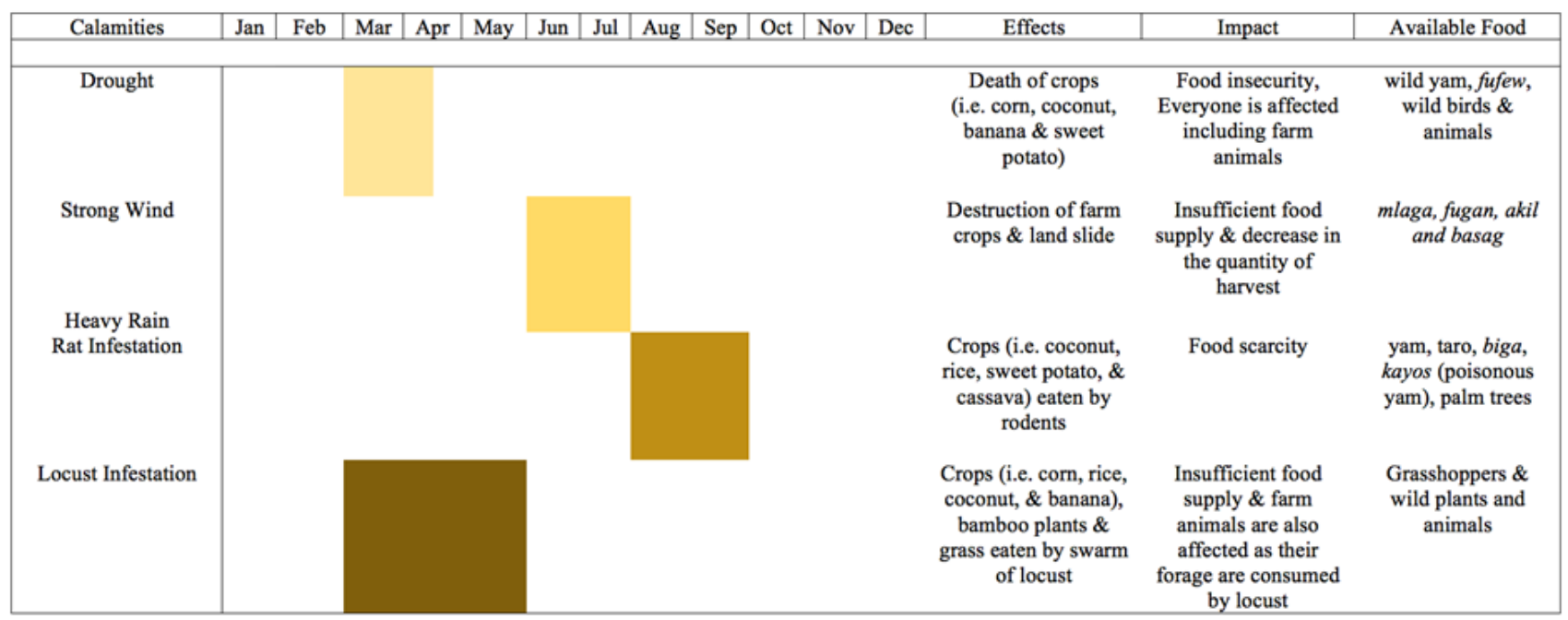

tribe. Moreover, healers from different Blaan villages usually travel and visit their relatives in other localities to share and learn traditional healing techniques from each other. Therefore, some components of the ethno-medical knowledge of the Blaans of Plinggang, Muling and Pongoleel may have emanated from other Blaan communities in Sarangani and South Cotabato. For instance, the healer of the tribe in Pongoleel admitted that she learned about the medicinal value of some plants and how to use to them from her fellow healer, who resides in a distant Blaan community at the foot of Mount Matutum.

As shown in Table 2, the Blaans have identified a wide-array of plants, which they claim to have medicinal and therapeutic effects. From the insiders' perspective, these plants are proven effective in treating different forms of diseases since ancient times. This knowledge is found to be useful to their survival. Most indigenous communities are geographically isolated and do not have access to modern medical practices and procedures, especially in the past. Even today, the Blaans in the hinterlands of Sarangani are still practicing traditional way of healing by using leaves, roots, barks and fruits of plants that grow in their locality. They also know the different methods of preparing and applying these medicinal plants to cure illnesses.

This plant-based pharmacopoeia is useful for both humans and animals. For instance, a certain weed locally known as slot is boiled and the concoction is given to persons with a bloated stomach. The plant also cures animals, particularly beasts of burden used for farming activities, such as cows, horses and carabaos, with bloated stom- achs. The Blaans call this medical condition as bungition. Most of these medicinal plants are utilized by the tribe to treat and cure human diseases more than as cure for animals.

Interestingly, these endemic plants are not only used to cure common medical conditions such as wounds, inflammation, vomiting, headache and stomach pain. The Blaans are claiming that some of these plants have therapeutic effects that can heal major and complicated illnesses. For example, the bark of the Maliango tree is claimed to be effective in curing the deadly malaria, while the ashes from the burnt trunk of the Sfali tree is useful in treating women with breast tumors (or even cancer). More examples include the concoction of roots of the Lago plant, which is given to a person who vomits blood; the roots of the Magangoh plant to cure migraine; and the use of Sakong leaves as topical medicine for eye infections. The Akbal tree is revered by the Blaans as a sacred plant and plays an important role in their traditional healing practices. The trunk of this tree is normally chopped and soaked in essential oil, which is typically used to stop the bleeding of wounds. This Akbal infused essential is claimed to be effective for snake and dog bites. Thus, the Blaans believe that the Akbal tree is potent to treat persons infected with venom and rabbis. Moreover, the tribe has the knowledge that the Baldangi plant is an antidote to the poison of Klot, a root crop which is normally consumed as food by members of the tribe during drought season.

Bio-pesticide, food storage and send banking system

To protect crops from the infestation of 
Table 2. Endemic plants with medicinal value.

\begin{tabular}{|c|c|c|c|}
\hline $\begin{array}{l}\text { Vernacular } \\
\text { name of plants }\end{array}$ & $\begin{array}{l}\text { Parts of plants use for } \\
\text { medication }\end{array}$ & $\begin{array}{l}\text { Methods of preparation and } \\
\text { application }\end{array}$ & Disease/ Medical condition \\
\hline Slot & leaves & $\begin{array}{l}\text { Burn the leaves and mix it in } \\
\text { hot water }\end{array}$ & Bloated stomach \\
\hline Alkik & leaves & $\begin{array}{l}\text { Use as rice wrapper cooked } \\
\text { in a bamboo pole }\end{array}$ & Head ache, vomiting, diarrhea \\
\hline Bia-o & fruits/nuts & $\begin{array}{l}\text { Burn the seed to extract the } \\
\text { oil and apply it to the fore- } \\
\text { head of a sick person }\end{array}$ & Convulsion (high fever) \\
\hline Maliango & bark & Boil the leaves in water & $\begin{array}{l}\text { Stomach pain, inflammation, } \\
\text { malaria }\end{array}$ \\
\hline Baldangi & bark & $\begin{array}{l}\text { Boil the bark and mix in klot } \\
\text { to remove its poison }\end{array}$ & $\begin{array}{l}\text { Food poisoning (antidote for } \\
\text { klot) }\end{array}$ \\
\hline$L o b$ & sap & Mix the sap with hot water & Women who recently gave birth \\
\hline Damay & leaves & Boil the leaves in hot water & Children who are vomiting \\
\hline Satbak & leaves & Boil the leaves in hot water & Children who are vomiting \\
\hline Akbal & trunk & Soak the trunk in coconut oil & $\begin{array}{l}\text { Snake bite, dog bite, stop bleed- } \\
\text { ing of wounds }\end{array}$ \\
\hline Gunoy & leaves & Apply the leaves to wounds & Wounds \\
\hline Aboh & leaves & $\begin{array}{l}\text { Apply the leaves to inflamed } \\
\text { parts of the body }\end{array}$ & Inflammation \\
\hline Kulat fateh & whole plant & $\begin{array}{l}\text { Burn the mushroom and ap- } \\
\text { ply it to inflamed wounds }\end{array}$ & Wounds, inflammation \\
\hline Sfali & trunk & $\begin{array}{l}\text { Burn the trunk and apply the } \\
\text { ashes to an infected breast }\end{array}$ & Breast tumor \\
\hline Balnabo' & bark & $\begin{array}{l}\text { Burn the bark and apply the } \\
\text { ashes to inflamed body parts }\end{array}$ & Inflammation \\
\hline Magangoh & roots & $\begin{array}{l}\text { Make a powder using roots } \\
\text { and mix it with breast milk }\end{array}$ & Migraine \\
\hline Lago’' & roots & Boil the roots in water & Persons who are vomiting blood \\
\hline Tablo' & leaves & Boil the leaves in water & Stomach ache \\
\hline Sakong & leaves & $\begin{array}{l}\text { Make a concoction using } \\
\text { young leaves and apply to } \\
\text { infected eyes }\end{array}$ & Eye infection \\
\hline
\end{tabular}


harmful insects, the Blaan people use indigenous organic pesticides and insecticides. One of these is salban, a variety of bamboo planted by the Blaans on the ground in their farms to protect crops from pestilence and even from barang or bad curse. Another organic insecticide used by the community is called abtok. Twigs of this bush plant are planted all over the rice fields to prevent the tia-ngaws or black bugs from attacking because of its foul smell. They also use sol, a concoction from a certain type of flower and sprayed to vegetables to manage pestilence in plants. Another function of sol is as an organic poison for catching fishes and shrimps in the streams of the Calminda Watershed. This traditional knowledge in dealing with pestilence is useful in the production of chemical-free crops and grains and therefore, a practice that is promoting green and organic agriculture.

Another important traditional practice that the Blaans have learned from their ancestors is the process of effectively storing foods. Rice and corn for consumption of the family are usually stored in $l e h u b$, which is a drum-like storage tank made from the bark of the Lob tree. The Blaans also driy poisonous klot or wild yam to make this root crop edible. The process of preparing and removing the toxic substance of klot is called kubong. Dried klot, according to them, can last even for years and can be utilized by the community when food is scarce. In addition, processed klot is usually mixed with rice for most local delicacies of the tribe. Accordingly, poison in wild yam can be washed away by soaking it in water mixed with salt. The community also identified the bark of the Baldangi plant as antidote to the poison of the wild yam.

Indigenous technology of preserving seeds and grains is a major aspect of the collective wisdom of the Blaans on disaster management that helps the community mitigate hunger and food insecurity. A bamboo canister called tiral is used by the community members as storage for a variety of seeds such as corns, rice, and beans. The Blaans save seeds of these crops and grains to ensure the continuity and survival of their varieties. Long period of droughts could wipe out the entire variety of crops, especially native corns, upland rice and beans. Another interesting way of storing corn seeds is known as blal. Corns with husk, in up-side -down position, are hanged in a row in an open field to be used in the next planting season. For people dwelling in the hinterlands and highly prone to many types of natural calamities, a knowledge on food storage and seed banking is highly valuable. This is an effective adaptive coping mecha- nism of the tribe that helps them survive economic shocks in times of disaster, particularly drought. Seed banking is important to ensure the continuity of the different variety of crops and grains, which could be destroyed and lost due to drought and other environmental hazards.

Forest management and social ownership of natural resources

The Blaans have practiced collective ownership of the lasang or forest and the bolol or mountain. Every member of the community owns the forest and all the natural resources found therein. Part of the social activities of the Blaan are mangayaw or hunting of wild boars, monkeys, dears and wild birds and the gathering of fruits of uway or rattan and blubo. The Blaans are innately generous; foreigners are even allowed to enter the lasang to gather resources there provided they have asked permission from the community leader, who is traditionally called fulong. This practice of protecting the forest is similar to the muyong of the Ifugaos in the Mountain Province (see Butic and Ngildo, 2002). The Blaans, though, are considerably more generous and accommodating as they allow foreigners or people who are not members of their tribe to enter and gather resources in the lasang, provided they have the permission of the fulong. In the case of the Ifugaos, non-members of the tribe are prohibited to go inside the muyong, especially to gather foods and hunt for wild birds and animals inside the forest. Severe punishments from members of the community are reserved for the intruders. Unfortunately, this old tradition of collective ownership of the forest is no longer practiced due to private ownership and land titling policy imposed by the Philippine Government. Moreover, these lands surrounding the Calminda Watershed are not yet recognized as an ancestral land of the Blaans and are thus open to possible acquisition and ownership of people outside the tribe.

Indigenous homestead and rituals in building houses

Another aspect of the indigenous knowledge system of the Blaans has something to do with functional architecture. The Blaans typically build their traditional houses in the hillside, not in the plain. A Blaan traditional house is made of indigenous materials, such as wood, bamboo, and cogon, that are abundant in the area. Nails are not used in building houses; rather, the Blaans use klay and nito in knitting together wood barks into bamboo poles that served as posts of the house. The Blaans also put bamboo braces to fortify the foun- 
dation of their houses to withstand the fury of strong winds during rainy seasons. The architectural design of Blaan houses is unique from other ethno-linguistic groups like the Tboli, although most of the building materials are the same. Its functionality to withstand different types of disasters is a result of age-long experience of the tribe to confront natural calamities.

The Blaans give significant attention to their superstitious beliefs in building houses. The tribe should be careful in choosing a place where to build a house. They make sure that the place is not within the path wherein bad spirits are traversing; otherwise, the family that settles therein might experience bad luck, particularly involving diseases and calamities. To determine a place in the community that is suitable for housing, a ritual called himbisan should be done. This is traditionally executed by the blu-os, who is a soothsayer, a priest, and a traditional healer of the community. However, the elders of the community admit that such traditional belief is no longer practiced by the tribe since no one in their community possesses the skill and knowledge to execute the rituals. The introduction of Christianity to this indigenous group has contributed to the disappearance of animistic beliefs nowadays.

\section{Community-based meteorology}

The members of the Blaan community claimed that they could determine the coming of dry and rainy seasons by observing the behavior of a certain tree, locally known as tlato'. Accordingly, they could predict drought if this tree shed off its leaves and proceed to flowering and bearing of fruits thereafter. However, if the tree started to produce new leaves and did not produce fruits, then rainy season is coming. The tlato' is a sacred tree for the Blaans. It does not only help predict the weather, its bark is also used in making lehub, a drum-like storage with a flooring made of sfali leaves, wherein grains of rice and corns for family consumption are stored. The use of plants or tree in indigenous early warning indicators of rainfall and drought is not exclusive to the Blaan tribe in the hinterlands of Sarangani. The indigenous people in the Makueni District in Swaziland, use the Baobab tree to predict drought and rainy seasons. At the end of long rains during March to April, the Baobab sheds all its leaves and remains leafless for the entire duration of the dry season in the month of June to September. Near the onset of short rains in October to November, tender new leaves start to appear on the tree. The fruiting pattern of the Baobab is also useful for the community to determine the performance of the season, especially rainfall failure and drought. Prolific fruiting seems to indicate a likely poor season ahead (UNEP, 2008).

\section{Indigenous knowledge on environmental con- servation}

Some aspects of the collective wisdom of the Blaan tribe is related to environmental protection and conservation, which has a significant connection to the culture and tradition of this group of people. This set of knowledge stresses the importance of some plants and animals and gives primacy to traditional farming practices of the tribe.

Sacred fauna and flora and indigenous farming system

Certain beliefs of the Blaans are beneficial for environmental conservation. There are plants and animals considered by the members of the community as sacred. Hence, the community has protected these plants and animals over the years. The alimukon or white-eared brown dove is hailed to be sacred because its sound serves as warning of an impending danger. For instance, if a group of hunters go inside the forest to hunt for wild animals and they hear the sound of the alimukon, hunting activities should be aborted, because they believe something wrong will happen to them inside the forest. Other sacred animals are horses and cows because of their usefulness in the farm; dogs as guardians; chickens and crabs in curing illnesses. Plants that are considered sacred include pali (rice), tubo (sugarcane), gabi (taro), kasila (camote), ube (yam) bukay agol (white corn) agol mlikat (glutinous corn) and kasila-kayo (cassava). These plants, particularly the root crops, are useful during drought, when food is scarce in the community. These are also important ingredients in the preparation of medicinal concoction to treat diseases of people and animals.

The Blaans are farming communities since time immemorial and the farming practices of their ancestors have been transmitted to the current generation. Traditionally, the Blaans plant vegetables and fruit bearing trees based on the position of the moon in the sky. According to these upland dwellers the best time to plant early maturing crops like camote, cassava and other vegetables is during alyawan (around 8:00 to 9:00 in the morning while the moon is still visible in the sky). Banana, mango and other fruit bearing trees are best planted during tasot-ibulan (around 1:00 to 2:00 in the afternoon, while the moon is in the eastern sky). The best time to plant coconut, taro and corn is during dsalibulan, when the moon in its fullest and nestling on the top of the mountain. Seeds of important crops 
are also saved by the community to be planted during the right season.

\section{Social network and coping mechanisms}

This section of the paper contains the discussion on the state of social capital of the Blaans and its importance in building community disaster resiliency. The researcher discusses various coping strategies of the Blaans in mitigating the chronic effects of different environmental hazards that confronted them over the years.

Social capital

Anthropologists and development workers put great emphasis to the importance of social capital in helping people affected by man-made and natural disaster to recover and rebuild their communities (see Ibañes, Buck, Khatchikian and Norris, 2004). International organizations, particularly the World Bank (1990), advocate the preservation of the social network, which is the primary source of social capital. In the study of Tobin, Whiteford, Murphy, Jones and McCarty (2004), of the communities in Ecuador and Mexico that are prone to volcanic eruption, it was found out that the psychological condition of people in communities with dense social networks are better-off compared to communities with weak or poor networks. Therefore, the network that is embedded in the social fiber of the community provides disaster-stricken population a sense of community support structure, which is helpful to their recovery from exposures to hazards. Moreover, social capital is understood as norms of reciprocity and network of civic engagement which are sources of mutual trust among members of the community. An analysis of the social network is vital to assess their capacities to confront impending disasters.

The Venn Diagram (Figure 3) shows a simple social network of the Blaans in the villages of Plinggang, Muling and Pongoleel. According to the participants of the social workshop, the purok or village leader, who is also the community tribal leader, is the primary source of support in the community when a disaster strikes. They also identified the Assembly of God, the most popular religious denomination in the locality, as a support organization during times of difficulties. Supports provided by the school teachers of Pongoleel Elementary School are also valued by the community. Moreover, the community also identified non-government organizations, religious institutions, Barangay Health Workers, Barangay Nutrition Scholars and local government units as infrequent sources of supports during times of disasters. Noticeably, the community did not identify the Barangay Captain of Alegria as a primary agent, to whom they could rely on especially during disasters. This apparent detachment of the community members from their Barangany Captain is due to the relative isolation and distance of the community from the barangay center. Moreover, The Blaans have a notable culture of self-help that is called alayon. During rice and corn harvests, every member of the community is enjoined to attend a feast to give thanks to the Almighty for the gift of abundant harvests. Hunting, a social activity among male members of the community, is usually done during feast time to offer food for the entire community.

Coping mechanism to mitigate hunger and food insecurity

Despite numerous natural disasters that constantly confront the upland communities, the Blaans have learned various survival mechanisms, most of which are taught by their ancestors. When there is food scarcity due to drought, community members resort to eating klot or poisonous wild yam to stave off hunger. According to the community, they are aware that wild yam contains poison, but they also know the appropriate way to make the klot edible. A certain plant called baldangi is used by the Blaan as antidote in case of food poisoning. Inquirer Mindanao reported on April 8, 2010 that 70 lumads had been confined to the hospital due to food poisoning after eating wild yam. This proves that the consumption of wild yam is common among different indigenous cultural communities in Mindanao.

Moreover, during times when rice and corns are scarce, these upland dwellers turn to their

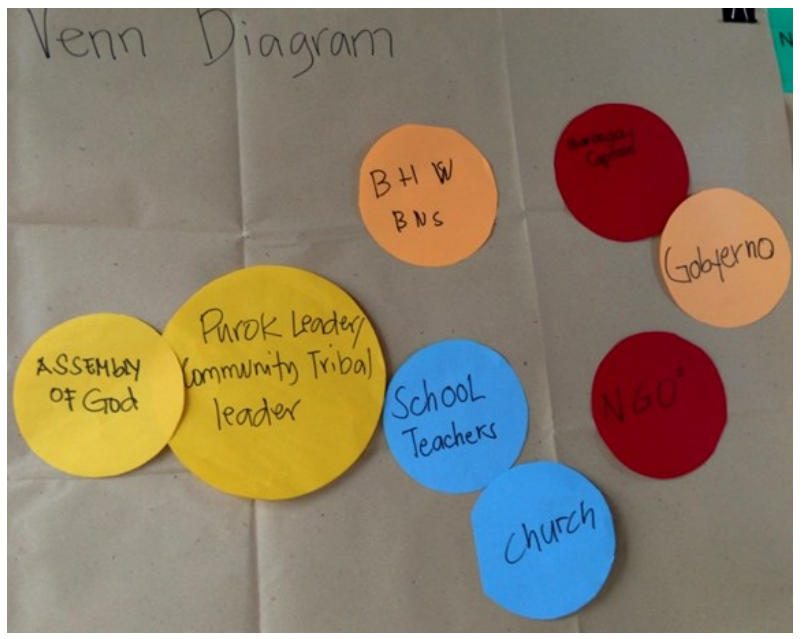

Figure 3. Venn Diagram of the social network of the Blaans 
natural food bank, located in the watershed area. Different endemic plants are gathered by the Blaans and consumed as alternative food. As shown in Table 3, the Blaans have identified different trees, vines and herbs, which fruits and leaves are edible and safe for human consumption.

Fufew is a common food variant that abundantly grows on the side of the cliffs and hills near the watershed. Other plants that thrive near the watershed such as silol, labi, mlaga, fugan and tlehe' also serve as sources of food for the community in times of hunger. Moreover, community members also gather wild fruits in the forest to provide food for the entire family. Unfortunately, the community reported that many of these trees have been cut down and are no longer existing in the watershed area.

The infestation of locust is detrimental to food production of the Blaans. To mitigate hunger, community members eat grasshoppers. Another notable coping mechanism of the tribe during food crises is the hunting of wild animals and birds in the forest and along the riverbanks. Blaans usually build a makeshift structure called lat that is made of palm leaves. Hunters hide inside the lat and wait for the wild animals and birds, which visit the streams to drink water. Inside the lat, hunters can conveniently hit their targets using bow and arrow without being noticed by the animals. Moreover, the Blaan folks also grow drought-resistant and quick-maturing crops like cassava, taro, beans and legumes.

\section{Erosion of Indigenous Knowledge}

In studying the traditional knowledge on flood preparedness of rural communities in Pakistan and Nepal, Dekens (2008) noted that this local knowledge is eroded due to rapid change in environmental and socio-economic context, which highlights the utility of external and scientific knowledge. This claim is also true in the case of the Blaans in the hinterlands of Sarangani. Community members, especially the elders, admitted that their collective knowledge on disaster management and environmental conservation is gradually eroding due to the influence of modern technology and mass media. The present generations of Blaans are no longer aware of the knowledge assets of their tribe. Most families do not possess knowledge of these traditional ways of dealing with disasters. Therefore, these practices are no longer transmitted to the younger members of the tribe. According to a senior member of the community, he is sharing the knowledge and practices he possesses to his children and grandchildren. However, he is also amenable to the diminishing interest among younger generations of Blaans in their community to learn about indigenous knowledge, especially in disaster management and environmental conservation. He noted that only few people in the community have the skill to perform the kubong, which is the process of preparing poisonous wild yam for food during drought season. He added that some of the community members no longer rely on farming as a source of living; instead, they are engaged in the cutting of trees to produce charcoal to be sold in the town center. This activity is detrimental to the health of the environment, especially to the Calminda Watershed. Most Blaan houses, if not all, in the hinterlands are no longer built using the original architectural design since they believe that concrete houses are more durable to withstand the devastation of natural disasters. In addition, most Blaan farmers no longer use indigenous pesticides like salban, abtok and sol due to the introduction of chemical-based pesticides for agricultural production.

\section{Conclusion}

The Blaans in the hinterlands of Sarangani have profound amount of indigenous knowledge system and practices on disaster management and environment conservation. This collective wisdom includes indigenous technologies on ethnomedicine, agriculture, food and seed banking, functional architecture, meteorology and forest management. From the insiders' perspective, the kanfulong de tribu or knowledge of the tribe is important to the members of the community to cope with and survive various forms of natural hazards. The widearray of plant-based pharmacopoeia is a major aspect of the knowledge system of the tribe on ethnomedicine. Although these plants have not been subjected to scientific investigation to determine their therapeutic properties, the Blaans believed that these herbs and other medicinal plants are effective in treating illnesses, which they have been doing since time immemorial.

Drought, heavy rains accompanied by strong wind, rat and locust infestations have been identified by the Blaans as major natural hazards that have confronted them over the years. Their exposures to these environmental hazards consequently result in hunger and food insecurity. To mitigate the devastating effects of natural disasters, the Blaans turn to the Calminda Watershed as their natural food bank, wherein they catch freshwater 
JHRS, Vol. 1, 2018

Table 3. Edible endemic plants in the natural food bank of the community.

\begin{tabular}{|c|c|c|}
\hline Vernacular name of plants & Type of plants & Parts of plants that are edible \\
\hline Klot & Vine (poisonous) & Roots \\
\hline Fufew & Herb & Young leaves \\
\hline Silol & Palm Tree & Leaves \\
\hline$L a b i$ & Palm Tree & Leaves \\
\hline Mlaga & Palm Tree & Leaves \\
\hline Fugan & Palm Tree & Leaves \\
\hline Tlehe' & Palm Tree & Leaves \\
\hline Blubo & Tree & Fruits \\
\hline Uway & Vine & Soft part of the rattan plant, fruits \\
\hline Fnuan & Herb (Ginger-like) & Roots \\
\hline Tulehgong & Tree & Fruits \\
\hline Kutay & Vine & Fruits \\
\hline Mlutag & Tree & Fruits \\
\hline Katabon & Tree & Fruits \\
\hline Abkalan & Tree & Fruits \\
\hline Blaw & Tree & Fruits \\
\hline Lebus & Tree & Fruits \\
\hline Lute & Tree & Inner trunks of the banana tree \\
\hline Salbuto' & Tree & Fruits \\
\hline Linol & Tree & Fruits \\
\hline Saging-bulig & Tree & Fruits \\
\hline Baldangi & Tree & Bark \\
\hline
\end{tabular}

fishes and hunt for wild birds and animals. They also gather wild fruits and leaves of wild plants and trees in the watershed to stave off hunger. The tribe is also consuming poisonous plants such as klot when food supply is insufficient, and they also use the baldangi plant as an antidote to the toxic substance from klot. Moreover, the social network of the Blaans, albeit simple, is found to be useful by the members of the community as source of support during times of difficulties, and therefore contribute to the building of community disaster resilience.

The profound knowledge system of the Blaans is gradually eroding due to the waning inter- est of the younger generations and the gradual disappearance of the natural landscape that serves as the social laboratory for the Blaans to learn and appreciate this knowledge asset. The old folks can no longer demonstrate and teach some of the major aspects of the kanfulong de tribu owing to the destruction of the forests, which heavily contributes to the dwindling health of the Calminda Watershed. Finally, the rapid disappearance of the forest is detrimental to the coping strategies of the Blaans in times of disasters. It also increases their levels of vulnerabilities to different forms of natural hazards as the forest in their major source of 
food and sacred hunting ground, when a disaster takes place in this hinterland community of Sarangani.

\section{Acknowledgment}

The researcher acknowledges the fieldwork assistance of Mr. Francis Brian Adlaon, Mr. Ronnie John Barrientos, Ms. Novie Mae Octaviano and Ms. Cheyzzer Ann Seva.

\section{References}

Aldrich, D. (2012). Building Resilience: Social Capital in Post-Disaster Recovery. London: The University of Chicago Press.

Borkhuu, B. (2008). Indigenous knowledge for disaster risk reduction of the Shiver Herder Community, Mongolia. In Shaw, R (eds), Indigenous Knowledge for Disaster Risk Reduction: Good Practices and Lessons Learned for Experience in the Asia-Pacific Region. International Strategy for Disaster Reduction. Retrieved from https:// www.unisdr.org/

files/3646_IndigenousKnowledgeDRR.pdf

Butic, M and Ngildo R. (2002). Muyong forest of Ifugao: Assisted natural regeneration in traditional forest management. Retrieved from http:// www.fao.org/docrep/004/AD466E/ad466e06.htm

Caverly, N. (2009). An Indigenous perspective on economic sustainability in mountain pine beetleaffected communities. BC Journal of Ecosystems and Management 10(2): 140-147. Retrieved from http://jem.forrex.org/index.php/jem/article/ viewFile/427/342

Dekens J (2008). Local knowledge on flood preparedness: Examples from Nepal and Pakistan in Shaw, R (eds), Indigenous Knowledge for Disaster Risk Reduction: Good Practices and Lessons Learned for Experience in the Asia-Pacific Region. International Strategy for Disaster Reduction. Retrieved from https://www.unisdr.org/ files/3646_IndigenousKnowledgeDRR.pdf

Edwards, P. (2015). A primer on watershed management. Journal of Contemporary Water Research \& Education, 154: 1-2. doi:10.1111/j.1936704X.2015.03184.x

Hewitt, K and Mehta M. (2012)/ Rethinking risk and disasters in mountain areas. Journal of Alpine Research, 100-1. DOI : 10.4000/rga.1653

Ibañes, B, Buck C, Khatchikian N, Norris F. (2004). Qualitative analysis of coping strategies among Mexican disaster survivors. Anxiety, Stress and Coping 17: 69-85

IFRC. (2015). Typhoon Haiyan: 18-month progress report. Retrieved from http://www.ifrc.org/Global/ Photos/Asia\%20Pacific/Report-Typhoon18month_Low.pdf

Komino, T. (2008). Indigenous coping mechanisms for disaster management in Frontier Province (NWFP), Pakistan. In Shaw, R (eds), Indigenous Knowledge for Disaster Risk Reduction: Good Practices and Lessons Learned for Experience in the Asia-Pacific Region. International Strategy for Disaster Reduction. Retrieved from https:// www.unisdr.org/ files/3646_IndigenousKnowledgeDRR.pdf

Lundberg, P. (2007). Use of traditional herbal remedies by Thai immigrants women in Sweden. In Pieroni and Vandebroek (eds) Traveling Cultures and Plants: The Ethnobiology and Ethnopharmacy of Migrations. Berghahn Books, New York

Mendoza, L, Guiam, R and Sambeli, L (n.d.). Mapping and Analysis of Indigenous Governance Practices in the Philippines and Proposals for Establishing an Indicative Framework for Indigenous People's Governance. Retrieved from https:// eprints.soas.ac.uk/4465/1/

Map-

ping_and_Analysis_of_Indigenous_GovernancePhilip-

pines_Participatory_Governance_Case_Study.pdf

Morris, M, Leung K, Ames, D and Lickel, B. (1999). Views from inside and outside: Integrating emic and etic insights about culture and justice judgment. Academy of Management Review, Vol. 24, No. 4, 781-796

Mucke, P. (2016). Logistics, infrastructure and risk analysis. In World Risk Report. Institute for Environment and Human Security, United Nations University. Retrieved from http://weltrisikobericht.de/ wp-content/uploads/2016/08/

WorldRiskReport2016.pdf

Nature Conservancy. (2017). Journey with nature: 
Watersheds 101. Retrieved from http:// www.nature.org/ourinitiatives/regions/ northamerica/unitedstates/indiana/ journeywithnature/watersheds-101.xml

Ososki, A, Balick, M, and Daly, D. (2007). Medicinal plants and cultural variation across Dominican rural, urban, and transnational landscapes. In Pieroni and Vandebroek (eds) Traveling Cultures and Plants: The Ethnobiology and Ethnopharmacy of Migrations. Berghahn Books, New York

Shaw, R, Uy, N and Baumwoll, J. (2008). Indigenous Knowledge for Disaster Risk Reduction: Good Practices and Lessons Learned for Experience in the Asia-Pacific Region. International Strategy for Disaster Reduction. Retrieved from https:// www.unisdr.org/

files/3646_IndigenousKnowledgeDRR.pdf

Syafwina. (2014). Recognizing indigenous knowledge for disaster management: Smong, early warning system from Simeulue Island, Aceh. Procedia Environmental Sciences, Vol. 24, 573-582

Takeuchi, Y and Shaw, R. (2008). Traditional flood disaster reduction measures in Japan. In Shaw et al. (eds), Indigenous Knowledge for Disaster Risk Reduction: Good Practices and Lessons Learned for Experience in the Asia-Pacific Region. International Strategy for Disaster Reduction, Retrieved from https://www.unisdr.org/

files/3646_IndigenousKnowledgeDRR.pdf

Tobin, G., Whiteford L., Murphy A., Jones E., and McCarty C. (2004). Modeling social networks and community resilience in chronic disasters: Case Studies from volcanic areas in Ecuador and Mexico. In P. Gasparini et al. (eds), Resilience and Sustainability in Relations to Natural Disasters: A Challenge for Future Cities, Springer Briefs in Earth Science, DOI: 10.1007/978-3-319-04316-6_2

Tuhiwai-Smith, L. (2012). Decolonizing Methodologies: Research and Indigenous Peoples, $2^{\text {nd }}$ Ed. London: Zed Books,.

UNEP. (2008). Indigenous Knowledge in Disaster Management in Africa. Retrieved from http:// www.icsu.org/icsu-africa/news-centre/news/

Appendix9IndigenousBookletUNEP.pdf

Uy, N and Shaw, R. (2008). Shaped by the wind and typhoon: The indigenous knowledge of the
Ivatans in the Batanes Islands. In Shaw et al. (eds), Indigenous Knowledge for Disaster Risk Reduction: Good Practices and Lessons Learned for Experience in the Asia-Pacific Region. International Strategy for Disaster Reduction. Retrieved from www.unisdr.org/

files/3646_IndigenousKnowledgeDRR.pdf

World Bank. (1990). Operational Directive on Involuntary Settlement. Retrieved from https:// www.ifc.org/wps/wcm/

connect/322d9d80488559f584b4d66a6515bb18/

OD430_InvoluntaryResettlement.pdf?

$\mathrm{MOD}=\overline{\mathrm{A}} \mathrm{JPERES}$ 